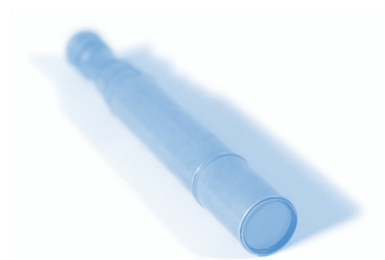

\author{
Elizabeth Stevenson \\ School of Chemistry \\ University of Edinburgh \\ Edinburgh \\ EH9 3JJ \\ e.stevenson@ed.ac.uk
}

\author{
Tony Lynch and \\ John Palfrey \\ Institute for Applied \\ Language Studies \\ University of Edinburgh \\ Edinburgh \\ EH8 9DP \\ a.j.lynch@ed.ac.uk \\ jpalfrey@yahoo.com
}

The University of

Edinburgh has been active in Public

Engagement with Science since the 1990s and provides training in

Science Communication for post-graduate students and

post-doctoral researchers, through its

'Transkills' (transferable skills) programme.

\section{Public engagement with a twist}

\begin{abstract}
An increasing number of post-graduate students and post-doctoral researchers in the College of Science and Engineering at the University of Edinburgh do not have English as their first language. Indeed some researchers have barely acquired the minimum standard of English required by the College. This hinders their own development as scientists and engineers and also has implications for undergraduate tutoring and laboratory demonstrating in their science and engineering disciplines. To address this issue, an English Language Skills course was developed in collaboration with the Institute for Applied Language Studies (University of Edinburgh). The course uses the techniques and activities of science communication training for Public Engagement in sessions dedicated to learning English. Part of the rationale was that students would find comfort and confidence in their scientific knowledge, and would therefore feel empowered to speak out and improve their English skills. This case study outlines the development and implementation of the course, includes feedback from the participants and observations on the course.
\end{abstract}

\section{Background}

The University of Edinburgh has been active in Public Engagement with Science since the 1990s and provides training in Science Communication for post-graduate students and post-doctoral researchers, through its 'Transkills' (transferable skills) programme. ${ }^{1}$ One such training programme, 'Science Communication in Action' (now 'Research Communication in Action') offers a course which combines both generic and subjectspecific science communication training, together with opportunities to gain experience in science communication in 'real' settings; for example in primary and secondary schools and at the Edinburgh International Science Festival. Elizabeth Stevenson from the School of Chemistry delivers both generic and chemistry-based training for 'Science Communication in Action'.

An increasing number of students enrolling for the course do not have English as a first language. Indeed, some students misunderstood the purpose of the course and assumed it was an English Language Skills Course as opposed to training for Public Engagement with Science.

Within the College of Science and Engineering there are growing numbers of international post-graduate students who have limited English language skills. Postgraduate students are encouraged to participate in undergraduate teaching activities such as laboratory demonstrating and delivery of tutorials, as part of their overall training. However, the limited English language skills can prevent some students from being involved in teaching activities, present difficulties for them integrating into their research groups and can limit their contributions at research group meetings. A quick survey of students with limited English language skills indicated that students would welcome additional language skills training.

The science communication training provided by 'Science Communication in Action' involves participation in different activities; for example role play, delivering and following instructions, explanation of science research in everyday language without the use of jargon, questioning and listening. The teaching of English as a second language now also tends to be activity based or task based ${ }^{2}$; for example map-reading, delivering and following instructions, questioning and listening.

Thus the 'experiment' was to explore the use of science communication training, together with science and engineering focused activities, to develop an English language skills course specifically for those students for whom English is not their first language. The rationale was that participants would be comfortable with the subject matter of the 
activity and thus feel empowered to speak out and improve their English language skills, with the additional bonus of developing skills and experience in Public Engagement.

\section{Development}

This concept was enthusiastically received by the Institute for Applied Language Studies at the University of Edinburgh ( $\mathrm{Mr}$ Eric Glendinning and Dr Tony Lynch) and by the Coordinator of 'Science Communication in Action' (Dr Briony Curtis), who assisted in the development of a pilot study. Activities were designed to generate real communication, as opposed to mere language practice, so some form of underlying 'gap' was built into each activity. Such gaps have been summarised by Prabhu ${ }^{3}$ in terms of information, opinion and reasoning. In an information gap task, the learners might each be given one of two different versions of a text, which they have to read and understand, before talking to a partner who has seen the other version, and they have to reconcile the two. In tasks involving an opinion gap everyone is given a text on a controversial topic, reads it and then debates the issue in pairs before coming together for a wider exchange of views. In a reasoning gap task, the learners are given enough information to be able to discuss a solution to a problem, but instead of being asked simply to choose and argue for a set of alternative solutions, they have to come up with a solution themselves.

After an initial pilot within the School of Chemistry, a format for a language skills course consisting of one initial half-day session followed by a one-hour session per week for six weeks was developed. Post-graduate students and postdoctoral researchers from the College of Science and Engineering were invited to attend.

\section{Experimental - what we did}

Week 1 (half-day session in three segments)

\section{Segment 1}

This consisted of a laboratory-based exercise using a simple science demonstration which was divided into two parts. The demonstration involved testing an acidic solution (vinegar) and a basic solution (sodium hydroxide) with Universal Indicator (model demonstration 1), followed by testing of 'Dry-Ice' 4 (solid carbon dioxide) together with an exploration of the property of sublimation (model demonstration 2). Key words were written on the white board as 'aide memoires' for the demonstration

- model demonstration 1 by Elizabeth Stevenson (ES) to students $(\mathrm{A}-\mathrm{H})$

- $\quad$ student demonstrations in parallel pairs: A- H (Instructors) to I- P ('Pupils')

- students I- $\mathrm{P}$ were asked to assume the role of 10 year olds.

Language feedback by Tony Lynch (TL)

- model demonstration 2 (by ES) to students I- P

- $\quad$ student demonstrations in parallel pairs: I- P (Instructors) to A- H ('Pupils')

- students $\mathrm{A}-\mathrm{H}$ were asked to assume the role of interested parents.

Language feedback by TL.

The activity described above is a science communication training activity used for native speakers to test their ability to give accurate instructions in a logical order without using scientific jargon and to answer questions in everyday language.

\section{Segment 2}

Jigsaw text: each student was given a different printed sentence from a paragraph of text which they memorised. Then they worked with the other students to sequence and finally dictate the paragraph. The paragraph we used was extracted from the School of Chemistry Safety Handbook from the Fire Regulations and Information. Language feedback (by $\mathrm{TL})$

\section{Segment 3}

Self-presentation on being a research student i.e. brief description of career to date.

Preparation of self-presentation by students In pairs: self-presentations ( $A$ to $B$, then $B$ to $A$ )

Plenary: each student presented information on the partner $(B$ about $A$ ) to whole group.

This is an exercise used in science communication training to help develop a) listening skills and b) the ability to describe one's area of research in everyday language.

Summary/Roundup on language (by TL)

\section{Week 2: Scientific questions}

Each student wrote their own question and feedback was given on the language. The topics could be drawn from any area of science. In groups of 3 or 4 , students related their questions and decided on the order in which they wished to discuss them. Questions were discussed for 15 minutes while being monitored. Language feedback was given. New groups were formed and they followed the same procedure, discussing the same questions but with different partners. Further feedback was given at the end of the session.

\section{Week 3: Text to Speech}

This was a two stage activity: stage 1 is a short piece of written homework; stage 2 took place in the class.

Stage 1

Students wrote a short text summarising one of the following topics:

- a controversy in their field of study

- an important area or a recent development in their field of study which they feel is not well known to the general public, but which they believe should be.

In class, working in pairs, they explained to each other orally the issue they had written about and answered any questions from their partner. The exercise was repeated with different partners.

\section{Week 4: Jigsaw reading/speaking (as described earlier and using a science based text)}

Week 5: Science writing in the media

This exercise comprised a discussion related to reporting of a scientific finding: a) to the public in a popular newspaper and b) to fellow scientists via an academic journal. This exercise is used in science communication training to explore different versions of the same story relayed for different audiences.

\section{Weeks 6 and 7: Short presentation on own area of research for a non-specialist audience followed by questions.}

This exercise is an integral section of 'Science Communication in Action' and allows participants to explore their choice of words and the level of explanation necessary 
for a non-specialist audience to engage with the science. Although the speaking activities varied in their use of oral and written information and students' own experiences, their common purpose was to create a natural platform for the students to practise communicating in English. The students work first in pairs (or trios, if there is an odd number of students), before coming together as a group for the post-task phase, in which they receive feedback from the language tutor (Tony Lynch or John Palfrey).

In contrast to the traditional language teaching procedure of 'presentation, practice, production' (PPP), in the task -based approach the language learners work through three phases, which have been characterised as rehearsal, performance and debriefing ${ }^{5}$. In the Pre-Task phase, they prepare for or rehearse the communication activity. During the Task phase they carry out the activity, typically in pairs or small groups; having completed the activity with one partner, they may move on to a new partner, since recycling of language activity has been shown to improve linguistic accuracy ${ }^{6}$. In the Post-Task phase or debriefing, the whole class come together to receive feedback on their performance; this may be based on observations by the teacher, perceptions from the learners, or both in combination.

While the pairs are carrying out their communication task, the tutor moves around the room, monitoring what they are saying and how they are saying it, and noting down points that they think should be brought to the group's attention after the task. One method of structuring the linguistic feedback is to categorise the tutor's comments under headings such as Vocabulary, Grammar, Stress (emphasis on a particular syllable) and Pronunciation. Issues of vocabulary and grammar are relatively straightforward; stress and pronunciation refer to different aspects of the way a student pronounces.

When the students have completed their speaking task, the tutor calls the class together and takes them through the points they have observed and noted down, grouping them by error types. Given that an additional aim of the course is to help the students communicate with non-specialists or nonscientists, it is also important that the tutor draws their attention to 'in-group' use of scientific terms and abbreviations, such as 'DNA sequence polymorphism data' and 'NMR' (mistaken for enema by the tutor!), which can be taken for granted when talking to fellow research students but which would not be understood by the public. Particular attention is also given to the specific use in science of everyday words such as 'element', 'basic', 'natural', etc.
Having worked through their points, the tutor asks the students to raise any other points themselves that occurred as they were engaged in the task, such as when they were unsure which of two words to use in context, or when they noticed that their partner seemed to be having difficulty understanding an expression they had used, and which they now want to check with the tutor. The airing of such doubts provides the opportunity for learners to fix in place or correct language points about which they would otherwise remain unsure, and the creation of this space for their discussion in the feedback phase is a valuable part of the tutor's role.

\section{Observations}

- The laboratory session proved to be an excellent icebreaker and fostered a comfortable atmosphere within the group.

- Participants appreciated the opportunity to be 'corrected' in their use of language.

- Participants found it relatively easy (compared to native speakers on Science Communication in Action courses) to describe their research in everyday language. The participant group consisted of students from chemistry, biology, maths, and informatics so it was appropriate that students used accessible language, not discipline-specific jargon, to communicate with each other. They were also able to gauge the level at which to engage their 'audience'.

- One group had some feedback for the Safety Committee in the School of Chemistry regarding the sentence order of the Fire Regulations and Information.

- In addition to language skills, students also expressed an interest for clarification of the cultural norms within a British academic institution.

- The biggest obstacle we faced was timetabling a slot when the majority of students were able to attend regularly.

- Feedback was very positive and students particularly liked the opportunity to deliver a short presentation on their research.

- Several students volunteered to assist in facilitating science workshops at the University of Edinburgh contribution to the Edinburgh International Science Festival (EISF) ${ }^{7}$.

\section{Quotes from students}

"I've really decided to learn English and the course was really good help on my way. I liked the way how we were 
encouraged to discuss topics that interest us. People were eager to speak in English and tell their opinions - at least I was. :) “

"The way we got feedback was cool: we could first discuss freely, without interruption, and then came the corrections. I like the lists of pronunciation, stress, vocabulary and grammar - that's more or less the way how I study English by myself. I think the points were really helpful - after every lesson I used some time to go through the difficult words mentioned in the lesson."

"I feel I've learned quite a lot! And about homeworks: it was good that we had some of them but not too often. I'm usually a bit critical of everything but now I don't have anything negative to say."

"Thanks a lot for your super English lessons. It was pleasure for me to be involved in your unique course. Your original approach to tuition is sure to help me in my further studying. Would you kindly inform me if you propose resuming such course."

\section{Summary}

Participation in EISF workshops was a useful experience for language learning because of the repetition and recycling ${ }^{6}$ in English language speaking during the facilitation of the workshops. The majority of participants in science festival workshops are young children, aged $\sim 8-12$, so clarity of instruction and simple language are essential.

The classes provided a useful two-way engagement experience between researchers of different disciplines and between the researchers and the language tutors.

The class proved popular with the participants and the tutors. However it was initially over-subscribed and some researchers were unable to reserve a place. Therefore we intend to facilitate parallel sessions with the assistance of Public Engagement practitioners from the School of Biological Sciences. This will provide a larger data set for feedback and analysis.

As a consequence of the increase in multidisciplinary research in science and engineering it is increasingly important that scientists, engineers and mathematicians are able to communicate effectively to specialists in disciplines other than their own. Therefore the skills/qualities required for public engagement, i.e. accurate communication of concepts at a level appropriate for the audience, are directly relevant to research.

\section{Acknowledgements}

The authors would like to thank the Graduate School of the School of Chemistry, University of Edinburgh for providing financial support for this project.

\section{References}

1. <www.transkills.ed.ac.uk/>

2. Willis, J. (1996) A Framework for Task-Based Learning. Harlow: Longman.

3. Prabhu, N. (1987) Second Language Pedagogy. Oxford: Oxford University Press.

4. The Education Department, Royal Society of Chemistry. (1995) Classic Chemistry Demonstrations: Royal Society of Chemistry.
5. Anderson, K.; Maclean, J. and Lynch, T. (2004) Study Speaking. Cambridge: Cambridge University Press.

6. Lynch, T. and Maclean, J. (2000) Exploring the benefits of task repetition and recycling for classroom language learning. Language Teaching Research 4/3: 221-250

7. <www.scieng.ed.ac.uk/Public_Engagement/ Discover_Science.asp> 